\title{
Continuity of Care and Patient Satisfaction in a Family Practice Clinic
}

\author{
MAJ Eric D. Morgan, MC, USA, COL Michael Pasquarella, MC, USA, and \\ CAPT John R. Holman, MC, USN
}

Background: Continuity is a tenant central to family practice. Continuity is associated with improved satisfaction in populations that can easily change providers. However, little is known about the importance of continuity where patients are assigned providers.

Methods: A pretested survey was distributed to patients of a family practice residency clinic in a military medical center for a week's period. Results were analyzed using $\chi^{2}$, unpaired $t$ test, correlation matrices, and linear regression for patient satisfaction.

Results: The response rate was $\mathbf{6 8 . 3 \%}$. Responders were not more likely to be seeing their primary care provider (PCP). Regression analysis revealed that $12 \%$ of patient satisfaction was associated with long-term continuity rates, $23 \%$ by PCP satisfaction, and $17 \%$ by how easy it was to make the appointment. For high clinic users (>10 visits/year), $78 \%$ of patient satisfaction is determined by PCP satisfaction and long-term continuity rates. A subset of patients (13\%) values choice of appointment time or other providers over PCP continuity. Satisfaction is not diminished in this group despite low long-term continuity $(P<.05$ for all results).

Conclusions: Patient satisfaction is associated with continuity, especially for high clinic users. Although continuity is important, a subset of patients values the ability to see other providers and to change providers. (J Am Board Fam Pract 2004;17:341-6.)

Continuity of care is described as a longitudinal relationship between patients and caregivers that transcends multiple illness episodes and includes responsibility for prevention and care coordination. ${ }^{1,2}$ Continuity of care is considered a cornerstone of family medicine. ${ }^{3-6}$

Patient satisfaction has been shown to be positively associated with continuity. ${ }^{7-10}$ However, this has been studied primarily in populations in which patients can easily change providers. It therefore becomes a "self-fulfilling prophecy"-if you are dissatisfied with care, you continue to change providers until you find one you like, who you then see often. Changes in health care plans may undermine this ability to choose and even remain with an individual physician. ${ }^{11}$ Health plans may also

Submitted, revised, 20 January 2004.

From the Department of Family Practice, Dwight D. Eisenhower Medical Center, Fort Gordon, GA (EDM); Fort Sam Houston, TX (MP); and the Department of Family Medicine, Naval Hospital, Camp Pendleton, CA (JRH). Address correspondence to CDR John R. Holman, Department of Family Medicine, Naval Hospital, Camp Pendleton, CA 92055 (e-mail: jrholman@cpen.med.navy.mil).

The opinions contained herein are those of the authors and should not be construed as official or as reflecting the views of the Department of the Navy, Department of the Army, or the Department of Defense. change physician panels, which might force patients to see a different physician from year to year. ${ }^{11-13}$

Patient satisfaction is an important predictor for patient retention. Patient satisfaction takes on increased importance in certain types of managed care medicine as income becomes dependent on the number of patients enrolled in primary care (capitated care). Patient satisfaction in a recent study was most influenced by the ease of access and perceived physician competence. ${ }^{14}$ Curiously though, this study did not evaluate the impact of continuity on satisfaction.

The purpose of this study was to understand the importance of continuity of care for patient satisfaction in an environment where patients are assigned a primary care provider with only a small amount of choice of who that provider is.

\section{Methods}

An anonymous, pretested waiting room survey was distributed to all patients being seen for an appointment at Family Medicine Clinic of Madigan Army Medical Center, Tacoma, Washington in December 1997 over a 1-week period. The Madigan Family Practice Department is a residency training pro- 
gram with more than 12,000 patients assigned to 38 providers. Patients are assigned to a provider panel, and efforts are made to comply with patient requests for a specific provider. However, if the requested provider panel is full, then patients are assigned to another provider. Patients may change providers based on availability by completing a provider change request form. A full range of medical care from newborn to geriatric including inpatient and maternity care is provided. Because it is a training program, less than half of the providers are present in clinic on any given day.

The survey instrument used a variety of 10point Likert scales, categorical variables, as well as broad descriptive data. Questions were drawn from previously validated surveys. The survey was an easy-to-complete 2 pages and was intended to be completed during the visit. The survey was pretested by a focus group of 10 patients and revised based on their recommendations.

Every patient who presented to the front desk for an appointment during the study week was invited to complete the survey. To give patients maximal time to complete the survey, surveys were given to patients as they signed in at the desk. Children younger than 8 had surveys completed by a parent. Approximately $40 \%$ of patients being seen during the study period declined to participate. The response rate is calculated from patients who accepted the survey and agreed to participate. Computerized records of the week's clinic visits were reviewed to determine any demographic differences between responders and nonresponders and between participants and nonparticipants.

The major outcome variable, patient satisfaction, was measured on both a categorical and Likert scale. The categorical scale was used as a compar-

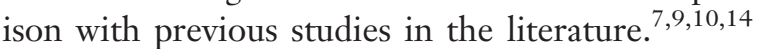
The Likert scale was used to assist in the regression analysis.

Data were analyzed using a variety of methods: $\chi^{2}$, unpaired $t$ test, correlation matrices, and univariate and multivariate regression for patient satisfaction. The multivariate regression analysis was created in a stepwise fashion. Variables entered into the model had been shown in previous studies to be associated with patient satisfaction: ease of access, the satisfaction with the primary care provider (PCP), the number of yearly appointments, and the proportion of appointments in the past year with the PCP (the long-term continuity rate). All vari- ables remained statistically significant $(P<.05)$. Appointment data were extracted from an electronic medical record. A final variable, whether the patient was active duty or a family member of an active duty soldier, was added after observing a significant reduction in global satisfaction in these groups. All variables remained significant.

\section{Results}

During the survey period, 448 patients were seen in the Family Practice Clinic (FPC). The front desk distributed 276 surveys. For those patients who accepted a survey, the return rate was $68.3 \%$. There were several differences between participants and nonparticipants. These are depicted in Table 1.

Table 2 displays survey results. Overall, family practice $(\mathrm{FP})$ patients are very satisfied with their care in the clinic. On the Likert scale, the average score was $8.7 ; 48 \%$ of respondents gave a perfect score. On the categorical scale, $97 \%$ of respondents described themselves as satisfied; nearly two thirds of those stated that they would recommend the clinic without any reservations to their friends (Figure 1). Despite impressive satisfaction scores, not all groups were equally satisfied. In particular, the spouses and children of active duty soldiers had significantly lower levels of satisfaction than all the other respondents.

Survey respondents reported that it was more important to see their PCP in the long term than it was for the immediate visit.(Table 2) Patients who were not able to see their provider for the immediate visit did not manifest lower satisfaction with their care $(P=.08$, unpaired $t$ test). Although not seeing one's assigned provider for the immediate visit did not lower satisfaction in a statistically sig-

Table 1. Differences between Survey Participants and Nonparticipants

\begin{tabular}{lccc}
\hline $\begin{array}{l}\text { Variable } \\
\text { (Patient Groups) }\end{array}$ & $\begin{array}{c}\text { Participants } \\
(\mathrm{n}=192)\end{array}$ & $\begin{array}{c}\text { Nonparticipants } \\
(\mathrm{n}=256)\end{array}$ & $P$ \\
\hline Active duty & $8.3 \%$ & $16.8 \%$ & .008 \\
Spouse of active duty & $24.5 \%$ & $23.8 \%$ & .87 \\
Child of active duty & $8.9 \%$ & $21.1 \%$ & .0004 \\
Retired & $23.4 \%$ & $10.5 \%$ & .0002 \\
Spouse of retired & $29.2 \%$ & $21.1 \%$ & .06 \\
Child of retired & $5.7 \%$ & $4.3 \%$ & .49 \\
Seeing PCP that day & $44.2 \%$ & $39.1 \%$ & .48 \\
\hline
\end{tabular}


Table 2. Descriptive Analysis of Survey Responses for All Patient Groups

\begin{tabular}{|c|c|c|c|c|c|}
\hline Patient & $\begin{array}{c}\text { FPC } \\
\text { Satisfaction }\end{array}$ & $\begin{array}{l}\text { Percentage } \\
\text { Continuity }\end{array}$ & $\begin{array}{l}\text { Ease of } \\
\text { App't }\end{array}$ & $\begin{array}{l}\text { Continuity } \\
\text { Importance }\end{array}$ & $\begin{array}{c}\text { PCP } \\
\text { Satisfaction }\end{array}$ \\
\hline All patients & 8.7 & 50.0 & 8.1 & 8.4 & 9.1 \\
\hline $\mathrm{AD}$ & 8.9 & 49.7 & 8.2 & 8.9 & 9.5 \\
\hline Spouses of $\mathrm{AD}$ & 8.2 & 52.1 & 8.1 & 8.0 & 9.0 \\
\hline Children of $\mathrm{AD}$ & 7.4 & 37.0 & 8.1 & 8.6 & 8.2 \\
\hline Retired & 9.1 & 49.0 & 8.1 & 8.7 & 9.5 \\
\hline Spouse of retired & 9.1 & 53.3 & 8.1 & 8.4 & 8.9 \\
\hline Children of retired & 9.1 & 46.5 & 8.1 & 7.7 & 9.0 \\
\hline ANOVA & $P=.003$ & $P=.73$ & $P>.99$ & $P=.56$ & $P=.22$ \\
\hline
\end{tabular}

FPC, family practice clinic; $\mathrm{AD}$, active duty; ANOVA, analysis of variance.

nificant manner, not seeing one's provider regularly over multiple visits was associated with significantly lower satisfaction. Those patients who were least likely to recommend the FPC to their friends manifested significantly lower long-term continuity rates (Figure 1). Those so dissatisfied with their FP care that they would discourage their friends from getting care at the FP clinic saw their provider only $3.7 \%$ of the time on average. In contrast, those so satisfied with their FP care that they would recommend the clinic without any reservations to their friends averaged seeing their provider $55.3 \%$ of the time.

Univariate and multivariate regression was done to determine the relationship of reported importance of long-term continuity, ease of appointments, and PCP satisfaction on overall FPC satisfaction. Results are depicted in Table 3.

On univariate analysis, increased yearly visits were not associated with satisfaction. However, with multivariate analysis, increased yearly visits were associated with decreased clinic satisfaction. This contrarian result (with most multivariate regression, variables tend to become less significant) prompted the multivariate regression to be repeated, stratifying yearly appointments into "low usage" ( $\leq 3$ appointments/year), "mid usage" (4 to 9 appointments/year), and "high usage" ( $\geq 10$ appointments/year). These regression results are depicted in Table 4. High-use patients had better continuity over multiple visits and higher PCP satisfaction than low-use patients, except for high-use active duty patients and their family members, who had much lower PCP satisfaction. Ease of appointments was more important for low-use patients.

\section{Discussion}

As American medicine moves away from managed care and toward consumer-driven medicine, improved patient satisfaction will take on increased importance. This study attempts to discern impor-

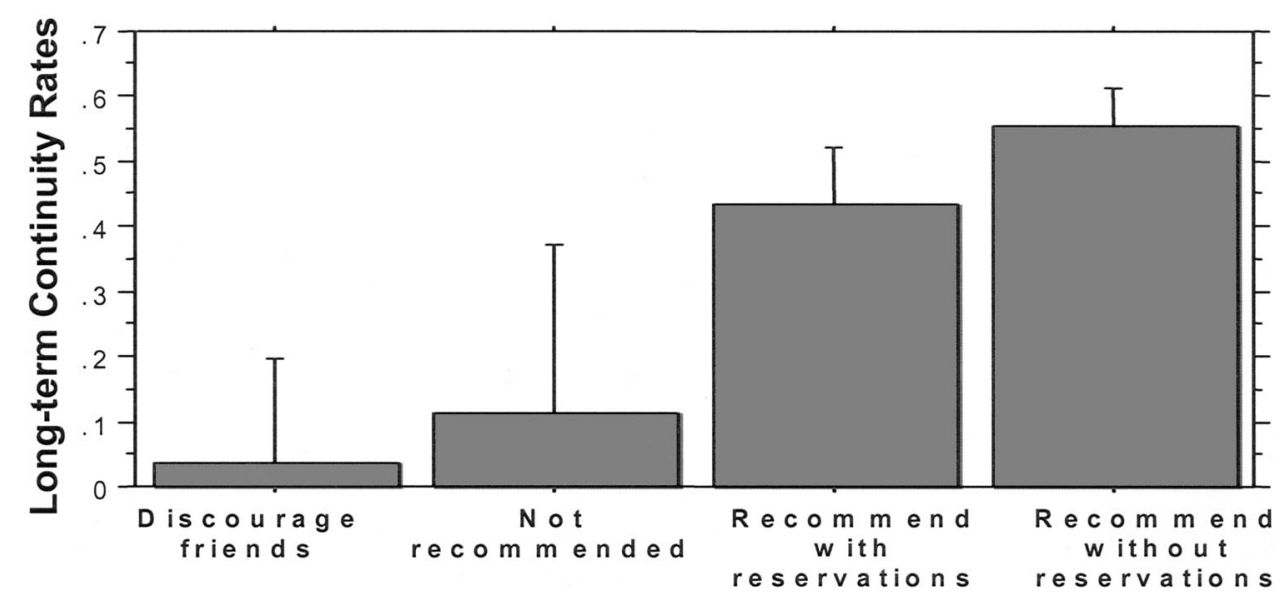

Figure 1. Long-term continuity rates for patient groups based on satisfaction with FP care. 
Table 3. Linear Regression for FPC Patient Satisfaction after Adjusting for Other Patient Preferences and Characteristics

\begin{tabular}{lcccc}
\hline Variable & Univariate Regression & \multicolumn{2}{c}{ Multivariate Regression } \\
\hline Continuity & $\beta$ & $P$ & 1.172 & .002 \\
Ease of appointment & 1.736 & $<.0001$ & .0 .166 & .0003 \\
PCP satisfaction & 0.196 & $<.0001$ & 0.251 & .0008 \\
Active duty (1)/Retired (0) & 0.338 & .0005 & -0.779 & .0007 \\
No. of yearly appointments & -0.907 & .1480 & -0.035 & .03 \\
\hline
\end{tabular}

Outcome variable $=$ Global FPC Satisfaction (on 10 point scale); $\mathrm{R}^{2}=0.316$.

tant determinants of satisfaction in patients that are enrolled in family practice. Patients reported excellent satisfaction with their care. Continuity, PCP satisfaction, and ease of scheduling appointments were important determinants of satisfaction. For high clinic users ( $>10$ visits/year) patient satisfaction was strongly correlated with PCP satisfaction and continuity. A subset of patients valued choice of appointment time or with other providers over PCP continuity. Satisfaction is not diminished in this group despite poor continuity rates.

Continuity of care is an important determinant of patient satisfaction. In particular, those who were most dissatisfied manifested abysmal continuity (Figure 1). In addition, obtaining continuity increases in importance with increasing frequency of visits. For high clinic users, continuity was a more important determinant than access. With this group, seeing a provider that one likes all the time (combining PCP satisfaction and long-term continuity on the regression) defines almost $75 \%$ of global satisfaction.

Repeating the multivariate linear regression stratified by annual usage illustrates several important points. With low usage patients, ease of scheduling appointments is a very important factor for satisfaction. This may indicate that patients who use the clinic infrequently are in relatively good health and are seen for occasional minor illnesses. They are probably young, working families with very busy schedules and have little discretionary time. Therefore, getting an appointment quickly at a convenient time is critical for them. Low- and mid-usage patients share very similar coefficients, which are very similar to those expected for all patients (nonstratified). Only for patients with high usage does the regression result change substantially. In particular, FPC satisfaction (on a 10-point Likert scale) more strongly correlates to PCP satisfaction and long-term continuity than to ease of access for appointments. This is not surprising because high-use patients are probably those with chronic medical conditions that require frequent follow up. This is similar to a recent study by Nutting et $\mathrm{al}^{15}$ that demonstrated patients who are sicker, at the extremes of age, and female value continuity with their primary care provider. $\mathrm{Pa}$ tients who develop a long-term relationship with a provider are more pleased with their care and, studies show, have better outcomes. ${ }^{16-19}$ With these findings, perhaps primary care providers should focus continuity efforts on those high-use patients

Table 4. Linear Regression for FPC Satisfaction after Stratifying for Amount of Annual Usage

\begin{tabular}{|c|c|c|c|c|c|c|c|c|}
\hline \multirow[b]{2}{*}{ Variable } & \multicolumn{2}{|c|}{ All Patients } & \multicolumn{2}{|c|}{$\begin{array}{l}\text { Low Usage } \\
(\mathrm{n}=47)\end{array}$} & \multicolumn{2}{|c|}{$\begin{array}{l}\text { Mid Usage } \\
(\mathrm{n}=87)\end{array}$} & \multicolumn{2}{|c|}{$\begin{array}{l}\text { High Usage } \\
(\mathrm{n}=52)\end{array}$} \\
\hline & $\beta$ & $P$ & $\beta$ & $P$ & $\beta$ & $P$ & $\beta$ & $P$ \\
\hline Continuity & 1.21 & .001 & 1.03 & .10 & 1.23 & .002 & 2.15 & .02 \\
\hline Ease of appointment & 0.17 & $<.001$ & 0.18 & .04 & 0.16 & .006 & 0.15 & .16 \\
\hline PCP satisfaction & 0.23 & .002 & 0.28 & .07 & 0.19 & .05 & 0.56 & .007 \\
\hline Active duty (1)/Retired (0) & -0.75 & .001 & -0.40 & .39 & -0.46 & .14 & -1.77 & $<.001$ \\
\hline
\end{tabular}

Outcome variable $=$ Global FPC Satisfaction (on 10 point scale); $\mathrm{R}^{2}$ for all patients $=0.295 ; \mathrm{R}^{2}$ for low usage $=0.335 ; \mathrm{R}^{2}$ for mid usage $=0.302 ; \mathrm{R}^{2}$ for high usage $=0.421$. 
who have more chronic disease and would potentially benefit more from increased continuity. Young, healthy families should have their primary care focused on rapid, easy access for their infrequent visits. This segment made up $13 \%$ of the FP population sampled during the survey. When patients enroll in Tricare, the military health insurance plan, they frequently do not have choice in their assigned primary care provider. This study finding would suggest that patients be given the ability to change providers should they be dissatisfied with their provider.

Limitations for this study include the generalizability of a study from an Army family practice clinic. In reality, the military health system is a vertically integrated managed health care system and is very similar to large health care maintenance organizations such as Kaiser or Group Health Cooperative. This is a survey, so reporting bias is a potential confounder. In fact, Table 1 shows more retired military patients responded to the survey than active duty patients. Retired patients may have more loyalty to the system than active duty patients who are not planning on a military career. On the other hand, retired patients may have had more experience with a variety of health care delivery systems, allowing a more accurate assessment of the care delivered.

Potential areas for further study include exploring other environments of care, such as nontraining group practices, other military services, and nonmilitary practices. A comparison of advanced or open access on the same aspects of continuity of care, provider satisfaction, and ease of appointments could be studied. The differences in satisfaction between active duty and retired patients needs to be explored, because the military health system exists primarily to care for the active duty patient.

There are several key points from the results of this study. Elucidation of barriers to access and exploration of the high clinic utilization would be important. There is the need to give patients choice of their provider, both for the immediate visit (to see someone else because of convenience purposes) and to change providers because of dissatisfaction. It is important to improve long-term continuity. Continuity becomes very important for patients that are being seen often in the clinic, and getting appointments with their PCPs should be facilitated. If this is neglected, dissatisfaction will increase. Although patient satisfaction was not decreased for the immediate visit, dissatisfaction will grow if the patients are continuously unable to access their provider. It would therefore seem advantageous to emphasize increasing the access for routine appointments. Open or advanced access models, in primary care clinics not associated with a training program, have the potential to increase both access and continuity of care. ${ }^{20,21}$ The results of open/ advanced appointing on access and continuity of care in primary care residency programs needs research.

\section{References}

1. Saultz JW. Continuity of care. In: Saultz JW, editor. Textbook of family medicine, 1st ed. New York: McGraw-Hill; 2000. p. 52-77.

2. Mc Whinney IR. Principles of family medicine. In: McWhinney IR, editor. A textbook of family medicine, 2nd ed. New York: Oxford University Press; 1997. p. $18-20$.

3. Hennen BK. Continuity of care in family practice. Part 1: dimensions of care. J Fam Pract 1975;2: 371-2.

4. McWhinney IR. Continuity of care in family practice. Part 2: implications of continuity. J Fam Prac 1975;2:373-4.

5. McWhinney IR. Continuity of care. J Fam Pract 1982;15:847-8.

6. Blankfield RP, Kelly RB, Alemagno SA, King CM. Continuity of care in a family practice residency program. Impact on physician satisfaction. J Fam Pract 1990;31:69-73.

7. Hjortdahl P Laerum E. Continuity of care in general practice: effect on patient satisfaction. BMJ 1992; 304:1287-90.

8. Freeman GK Richards SC. Is personal continuity of care compatible with free choice of a doctor? $\mathrm{Pa}-$ tients' views on seeing the same doctor. Br J Gen Prac 1993;43:493-7.

9. Dietrich AJ Marton KI. Does continuous care from a physician make a difference? J Fam Pract 1982;15: 929-37.

10. Flocke SA. Measuring attributes of primary care: development of a new instrument. J Fam Pract 1997; 45:64-76.

11. Kahana E, Stange KC, Meehan R, Raff L. Forced disruption in continuity of primary care: the patients perspective. Social Focus 1997;30:177-87.

12. Flocke SA, Stange KC, Zyzanski SJ. The impact of insurance type and forced discontinuity on the delivery of primary care. J Fam Pract 1997;45:129-35.

13. Kikano GE, Flocke SA, Gotler RS, Stange KC. 'My insurance changed': the negative effects of forced discontinuity of care. Fam Pract Manag 2000; $7: 44-5$. 
14. Meng YY, Jatulis DE, McDonald JP, Legorreta AP. Satisfaction with access to and quality of health care among Medicare enrollees in a health maintenance organization. West J Med 1997;166:242-7.

15. Nutting PA, Goodwin MA, Flocke SA, Zuzanski SJ, Stange KC. Continuity of primary care: to whom does it matter and when. Ann Fam Med 2003;1:14955.

16. Tsuji-Hayashi YS, Fukuhara, Green J, Kurokawa K. Use of prescribed drugs among older people in Japan: association with not having a regular physician. J Am Geriatr Soc 1999;47:1425-9.

17. Christakis DA, Wright JA, Koepsell TD, Emerson $\mathrm{S}$, Connell FA. Is greater continuity of care associated with less emergency department utilization? Pediatrics 1999;103:738-42.
18. Gill JM, Mainous AG, Nsereko M. The effect of continuity of care on emergency department use. Arch Fam Med 2000;9:333-8.

19. Christakis DA, Mell L Koepsell TD, Emerson S, Connell FA. Association of lower continuity of care with greater risk of emergency department use and hospitalization in children. Pediatrics 2001;107:524-9.

20. Murray M, Tantau C. Same-day appointments; exploding the access paradigm. Fam Pract Manag 2000;7:45-50.

21. Forjuoh SN, Averitt WM, Cauthen DB, Couchman GR, Symm B, Mitchell M. Open-access appointment scheduling in family practice: comparison of a demand prediction grid with actual appointments. J Am Board Fam Pract 2001;14:259-65. 